INDUSTRIAL SCALE PROCESSING AND ELEVATED TEMPERATURE

PROPERTIES OF $\mathrm{Ni}_{3} \mathrm{~A} 1-\mathrm{Cr}-\mathrm{Zr}-\mathrm{B}$ ALLOYS*

V. K. Sikka

Metals and Ceramics Division

Building 4508; MS 083

Oak Ridge National Laboratory

P. 0. Box 2008

Oak Ridge, Tennessee 37831
E. A. Loria

Meta1lurgica1 Consultant

1828 Taper Drive

Pittsburgh, Pennsylvania 15241

\title{
Abstract
}

This study is the first to evaluate the elevated temperature properties of two of the strongest $\mathrm{Ni}_{3} \mathrm{Al}-\mathrm{Cr}-\mathrm{Zr}$ alloys when made in sufficient quantities and processed to products simulating industrial-scale operations. The technologies considered are powder processing, melting techniques, near-net-shape processes, and cold and hot working of cast products. The tensile properties from ambient to $1100^{\circ} \mathrm{C}$ and creep rupture properties in the range of 704 to $1093^{\circ} \mathrm{C}$ are presented. These properties are most sensitive to the grain size differences produced by the various processing techniques. The results compare favorably with those obtained on commercial superalloys and reveal good potential for elevated temperature structural use.

${ }^{*}$ Research sponsored by the Division of Materials Sciences, U.S. Department of Energy, under contract DE-AC05-840R21400 with Martin Marietta Energy Systems, Inc.

Superalloys 1988

Edited by S. Reichman, D.N. Duhl,

G. Maurer, S. Antolovich and C. Lund

The Metallurgical Society, 1988 
Alloys based on the ductile-ordered intermetallic compound $\mathrm{Ni}_{3} \mathrm{Al}$ are being considered for a range of structural applications (1-3). These include gas and steam turbines, automotive pistons, turbochargers and valves, heating elements for appliances, aircraft fasteners, gas and oil well tubular products, and components for corrosive environments. Acceptance will depend on the development of the processing technology and the mechanical properties of various products for these applications. With this in mind, a study was conducted on the effect of processing scaled up quantities of two $\mathrm{Ni}{ }_{3} \mathrm{Al}-\mathrm{Cr}-\mathrm{Zr}-\mathrm{B}$ alloys by six different methods and determining their elevated temperature tensile, creep, and rupture properties. The two alloys (IC-218 and IC-221) provide improved high-temperature strength via solid solution-hardening effects of 0.8 or 1.7 wt $\% \mathrm{Zr}$, while the $7.8 \mathrm{wt} \% \mathrm{Cr}$ alleviates dynamic embrittlement by changing the oxidation process. To accommodate these elements, the aluminum content is reduced from 11.3 to $8.5 \mathrm{wt} \%$ and boron remains at $0.02 \mathrm{wt} \%$. The IC-218 and IC-221 alloys are primarily ordered structure ( $\gamma^{-}$-phase) with small amounts of the disordered structure ( $\gamma$-phase) at room temperature. The fraction of disordered structure in these alloys increases at high temperatures (greater than $1000^{\circ} \mathrm{C}$ ). On the other hand, IC-50 (11.3A1-0.6Zr-0.02B) has only the ordered structure ( $\gamma^{\prime}$-phase) up to its melting point, but it lacks the high-temperature ductility of the chromium-containing alloys.

\section{Materials and Processes}

This study is the first to evaluate materials made in sufficient quantities and processed to products simulating industrial-scale operations. Because of expected restricted hot workability and its negative effect upon a number of possible applications, various processing techniques have been explored for the determination of elevated temperature properties. These include powder metallurgy (PM) techniques utilizing 125 to $250 \mathrm{~kg}$ of powder from two atomizing sources which were either hot isostatic pressed (HIP) or consolidated under atmospheric pressure (CAP) and then extruded to bar stock. Also, sma11 isotherma11y forged disks and rapid omnidirectional compacted (ROC) disks were produced from the two PM processes. Melting and casting 50to $250-\mathrm{kg}$ air-induction melt (AIM) or vacuum-induction melt (VIM) heats as well as duplexing via electroslag remelting (ESR) provided cast billet and hot extruded products. Cast tube hollows of $125-\mathrm{mm}$ OD and $25-\mathrm{mm}$ wall were produced from argon-induction melting of $250-\mathrm{kg}$ heats as well as $15-\mathrm{kg}$ castings and twin roller cast sheet of $200-$ to $250-\mathrm{mm}$ width and 1.5 - to 2.0-mm thickness were produced from 50-kg AIM heats. Flowcharts describing the status of each of these processes investigated by the Oak Ridge National Laboratory (ORNL) in conjunction with industry have been presented (4).

For testing purposes, sheet specimens were used principally to reduce machining cost. This was the case for the VIM-extruded, ESR-extruded, AIM-extruded, cast billet-cold rolled, twin-roller sheet, and PM-extruded specimens. Although extruded products were sheet or round bar, sections from these were cold rolled and annealed to a thickness of $0.76 \mathrm{~mm}$. Round specimens of $6.4-\mathrm{mm}$ diam were prepared from cast billet as well as $3.2-\mathrm{mm}-\mathrm{diam}$ subsize rounds which were cut from an isothermal and an ROC disk prepared from the PM products. Tensile tests were conducted on four Instron machines, using sheet specimens of $0.76-\mathrm{mm}$ thickness by $25-\mathrm{mm}$ gage length. In all cases, a constant crosshead rate was used rather than strain rate. Most commonly used was $8.3 \times 10^{-4} / \mathrm{s}$ (because of ASTM requirements), but $3.3 \times 10^{-3} / \mathrm{s}$ was used on some tests. Several tests were conducted at a range of strain rates to explore superplasticity and effects on strength and ductility. A11 creep tests were constant load tests. Those on sheet specimens were conducted using dead-load creep machines. Creep tests on 6.4-mm-diam round 
specimens were conducted using a lever-arm machine with lever-arm ratios of $12: 1$ or $20: 1$. For all sheet specimens, strain was measured by extension of the pull rod by a mechanical dial gage. For round specimens, an attached strain-averaging extensometer provided strain measurements. For all cases, strain-time data were computer plotted and analyzed for minimum creep rate and other quantities such as start of second-state creep, start of thirdstage creep, etc. Ruptured specimens were measured for fracture strain and reduction of area.

\section{Resu1ts}

The grain size of six products of IC-218 vary between 9 and $21 \mu \mathrm{m}$ for three different PM processes, cast and hot extruded and cast and coldrolled sheet versus $727 \mu \mathrm{m}$ in cast tube hollow, per Figure 1. The tensile
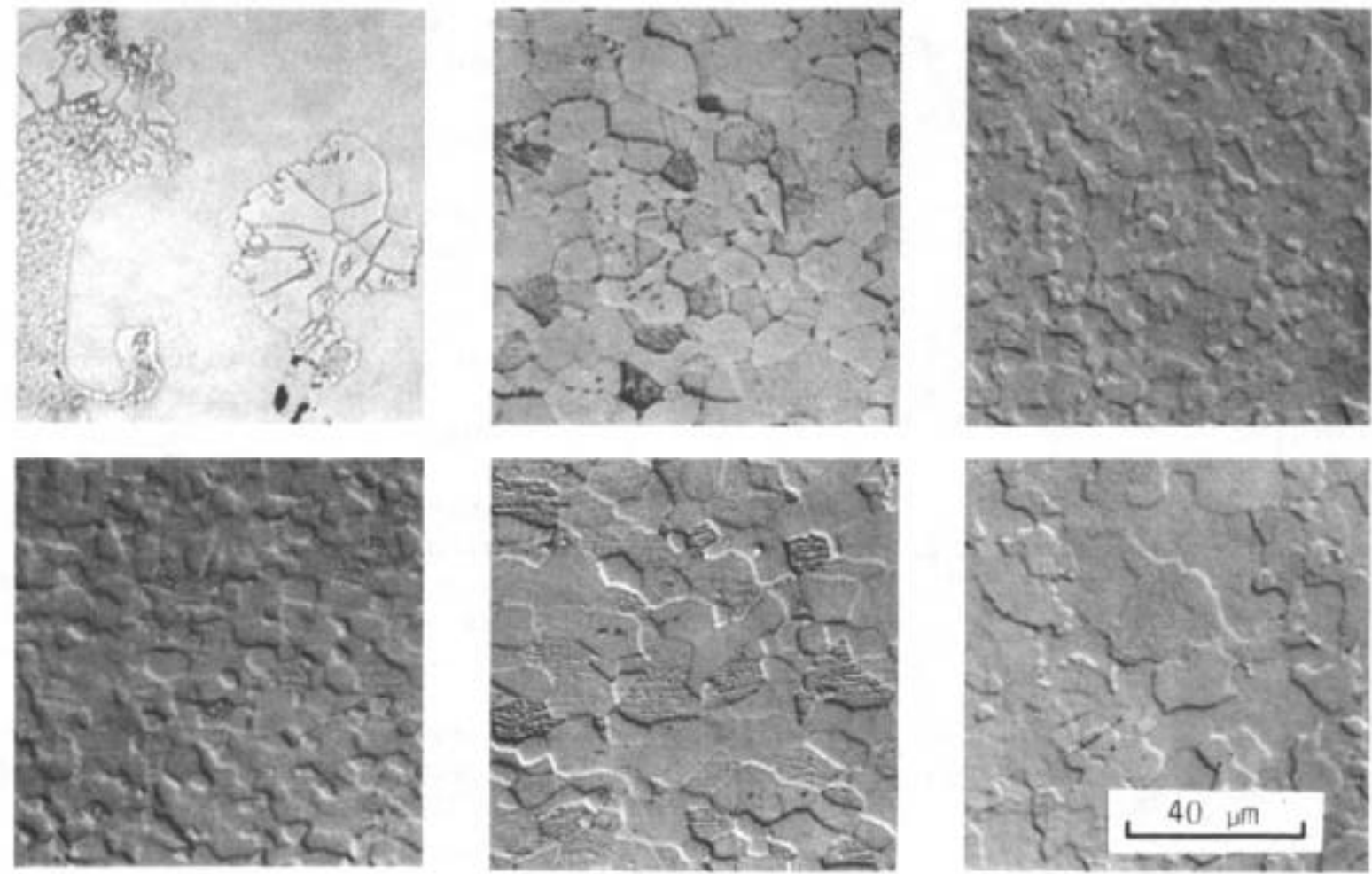

Figure 1 - Optical microstructure of IC-218 alloy specimens processed by six different processes. (a) Cast tube hollow, grain size $=727 \mathrm{um}$; (b) cast and hot extruded, grain size = $11 \mu \mathrm{m} ;(c)$ cast and cold-rolled sheet, grain size $=16 \mu \mathrm{m} ;$ (d) powder extruded, grain size = $16 \mu \mathrm{m}$; (e) powder isothermal disk, grain size $=9 \mu \mathrm{m}$; and $(f)$ powder ROC disk, grain size $=21 \mu \mathrm{m}$. Magnification: $500 \times$.

properties, plotted from ambient to $1100^{\circ} \mathrm{C}$, show a band of values for $0.2 \%$ yield strength, ultimate strength, and total elongation, per Figure 2 . Yield strength is one of the more fundamental properties of a structural alloy. It is a property to be maximized and, in the case of elevated temperature applications, to be invariant with temperature. The yield strength of the five fine-grain products remains stable within a band of 550 to $750 \mathrm{MPa}$ up to $600^{\circ} \mathrm{C}$, then declines gradually within 400 to $600 \mathrm{MPa}$ at $800^{\circ} \mathrm{C}$ then declines sharply to below $100 \mathrm{MPa}$ at $1100^{\circ} \mathrm{C}$. The coarse-grain tube hollow has the lowest yield strength of all products at room temperature of $450 \mathrm{MPa}$, which rises gradually to the highest value of all products of $680 \mathrm{MPa}$ at $800^{\circ} \mathrm{C}$ and then declines to still the highest value of $250 \mathrm{MPa}$ at $1100^{\circ} \mathrm{C}$. The ultimate strengths of the five fine-grain products decline gradually within a band of 1250 to $1500 \mathrm{MPa}$ at room temperature to 520 to 
$650 \mathrm{MPa}$ at $800^{\circ} \mathrm{C}$, while the coarse-grain cast product which has a much lower strength of $750 \mathrm{MPa}$ at room temperature maintains it to $800^{\circ} \mathrm{C}$. All products then decline in the same manner to $1100^{\circ} \mathrm{C}$ with the latter still exhibiting
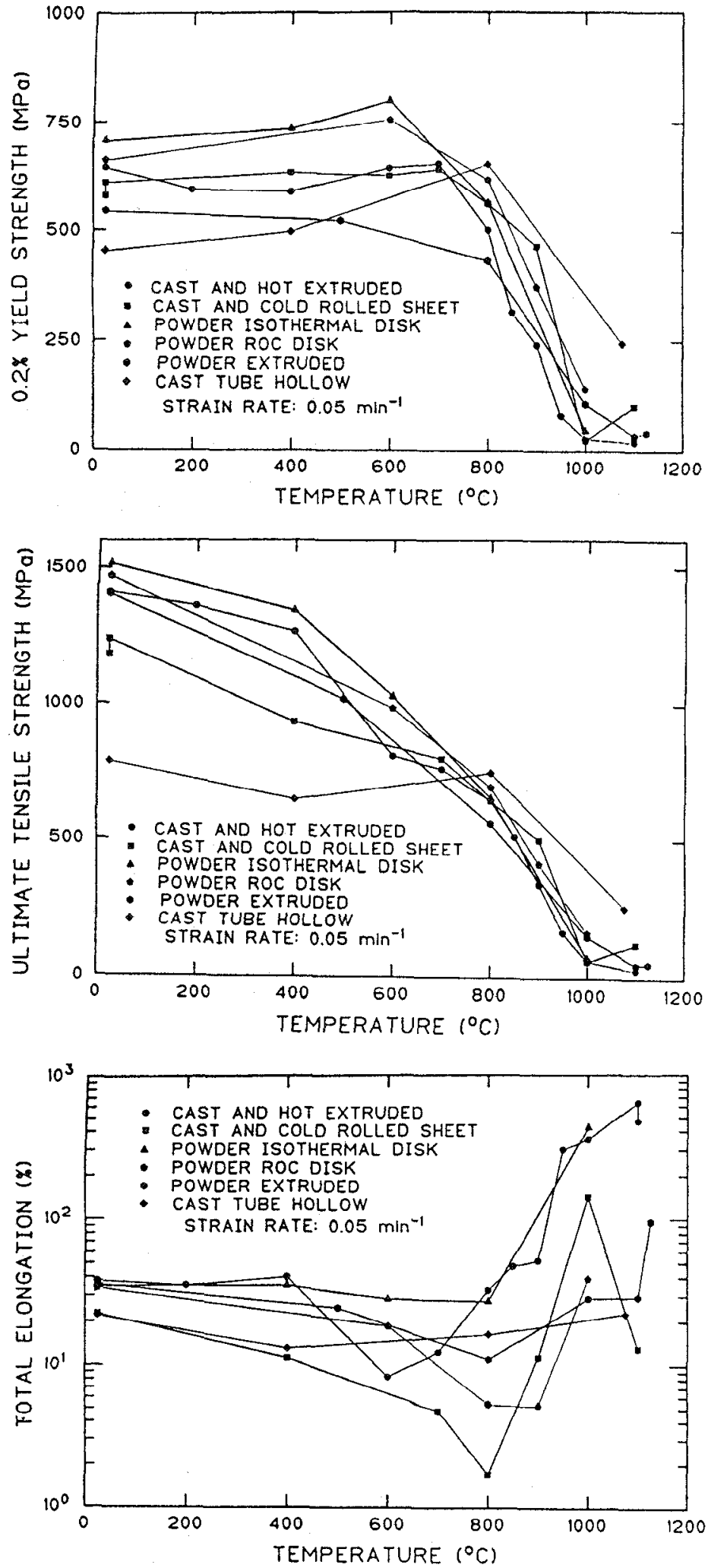

Figure 2 - Tensile properties comparison for IC-218 alloys processed by six different processes. All tests were conducted at a strain rate of $0.05 / \mathrm{min}$ $\left(8.3 \times 10^{-4 / s}\right)$. the highest strength. The total elongation of all six products is within 20 to $38 \%$ at room temperature and the range then widens between 7 and $35 \%$ at $800^{\circ} \mathrm{C}$ in five products, followed by a sharp rise to values exhibiting superplasticity at $1000^{\circ} \mathrm{C}$. The $20 \%$ elongation of the cast tube hollow only declines to $15 \%$ at $800^{\circ} \mathrm{C}$ and shows no superplasticity at $1075^{\circ} \mathrm{C}$. Unexpectedly, the $22 \%$ elongation in cast and cold-rolled sheet product, having a fine-grain size of $16 \mu \mathrm{m}$, declines continuously to a nil ductility value at $800^{\circ} \mathrm{C}$ and then rises sharply to a superplastic value of $260 \%$ at $1000^{\circ} \mathrm{C}$.

The IC-221 alloy was processed by similar techniques used for IC-218 alloy. The same trends in grain size and tensile were observed in IC-221. When compared under the same conditions with IC-218 (i.e., finegrain PM-extruded product), the yield and tensile strength of IC-221 are higher than IC-218, see Figure 3 . The IC-221 a1loy maintains its yield strength of $635 \mathrm{MPa}$ up to $800^{\circ} \mathrm{C}$, while IC-218 declines slightly from 525 to $435 \mathrm{MPa}$ at $800^{\circ} \mathrm{C}$, then both decline rapidly to $100 \mathrm{MPa}$ at $1000^{\circ} \mathrm{C}$. Ultimate strength declines gradually from $1500 \mathrm{MPa}$ for IC-221 versus $1400 \mathrm{MPa}$ for IC-218 to $690 \mathrm{MPa}$ versus $550 \mathrm{MPa}$ at $800^{\circ} \mathrm{C}$ and then to the same $120 \mathrm{MPa}$ at $1000^{\circ} \mathrm{C}$. E1.ongation values are the same at $35 \%$ at room temperature, with a gradual decrease to a minimum of $11 \%$ at $800^{\circ} \mathrm{C}$ in $\mathrm{IC}-218$ compared to an unexpected deep decline from $28 \%$ at $600^{\circ} \mathrm{C}$ to $5 \%$ at $800^{\circ} \mathrm{C}$ in IC-221. Then, there is the usual steep ascent at 1000 to $1100^{\circ} \mathrm{C}$. It is noteworthy that the room temperature ductility of the various IC-218 and IC-221 products is sufficient for conventional mill material handling and shipping operations. 
The effects of grain size on tensile properties of $\mathrm{Ni}_{3} \mathrm{Al}$ produced in smal1 (1aboratory) quantities have been extensively studied (5-6). Reducing the grain size has been found to significantly increase the room-temperature strength with relatively little effect on the ductility. Our results on industrial-scale processing of larger quantities reveal superior yield and ultimate strength from ambient to $700^{\circ} \mathrm{C}$ for fine-grain products versus

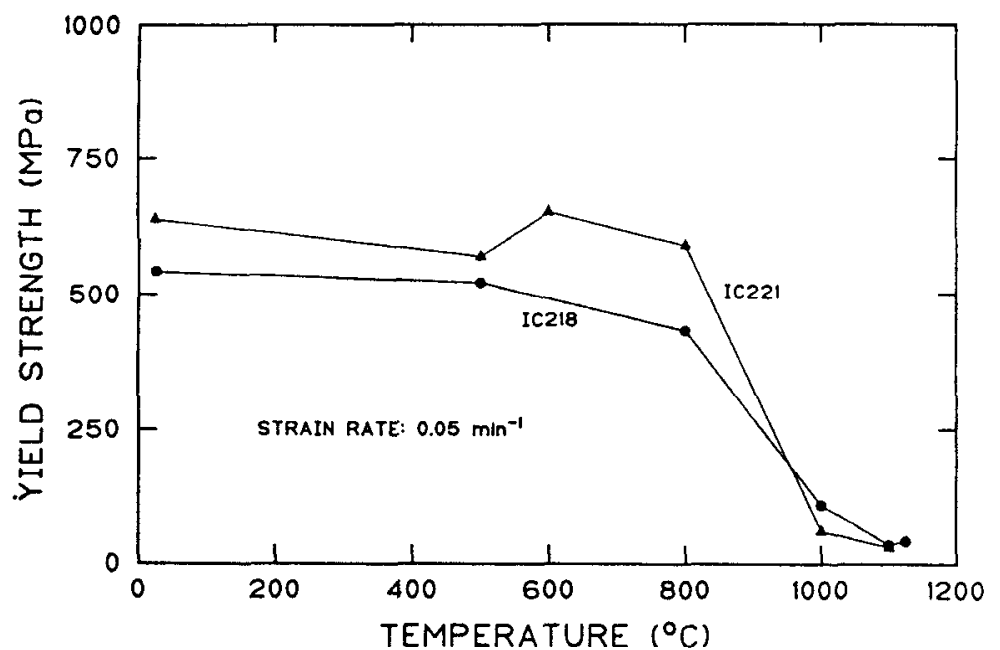
coarse-grain cast products, but the latter remain stable and gradually increase to the highest strength values at $800^{\circ} \mathrm{C}$. This change is brought about by the increase in lattice resistance to slip and the decrease in the effectiveness with which grain boundaries impede slip as temperature rises. Above $950^{\circ} \mathrm{C}$, a fine-grain product produced by either extrusion of cast billet or extrusion of powder shows superplastic behavior, whereas coarse-grain cast product shows higher strength and low ductility (2-3).

Creep tests over a temperature range of 649 to $871^{\circ} \mathrm{C}\left(1200\right.$ to $\left.1600^{\circ} \mathrm{F}\right)$ and times from 10 to $12,464 \mathrm{~h}$ provided data for analysis using the Larson-Miller parameter, see Figure 4 . Plotting creep-rupture strength versus parameter value produces a narrow band of values, represented by a single line of negative slope, for the five finegrain products and a separate single line for the coarse-grain castings of IC-221. At each stress level, the parameter is significantly higher in the case of the latter, which translates to a higher rupture strength at the same parameter value. On the other hand, the corresponding values for total elongation and reduction of area for the fine-grain products are significantly higher than those for castings over the entire parameter range, and the data, in each case, are represented by a single 
positive slope line. A1so, it is apparent that fine-grain material from cast billets provides higher values than fine-grain material from powder billets so that separate lines are drawn differentiating these two fine-grain products. In general, the same trends are observed in comparing IC-218 finegrain products with very coarse-grain $(6600 \mu \mathrm{m})$ cast billet, per Figure 5 . The plotting of the data for fine-grain products of IC-218 reveals that separate lines separating $14-$ to $16-\mu \mathrm{m}$ grain size from $7-$ to $10-\mu \mathrm{m}$ grain size are drawn which show that the former has a higher rupture strength but lower
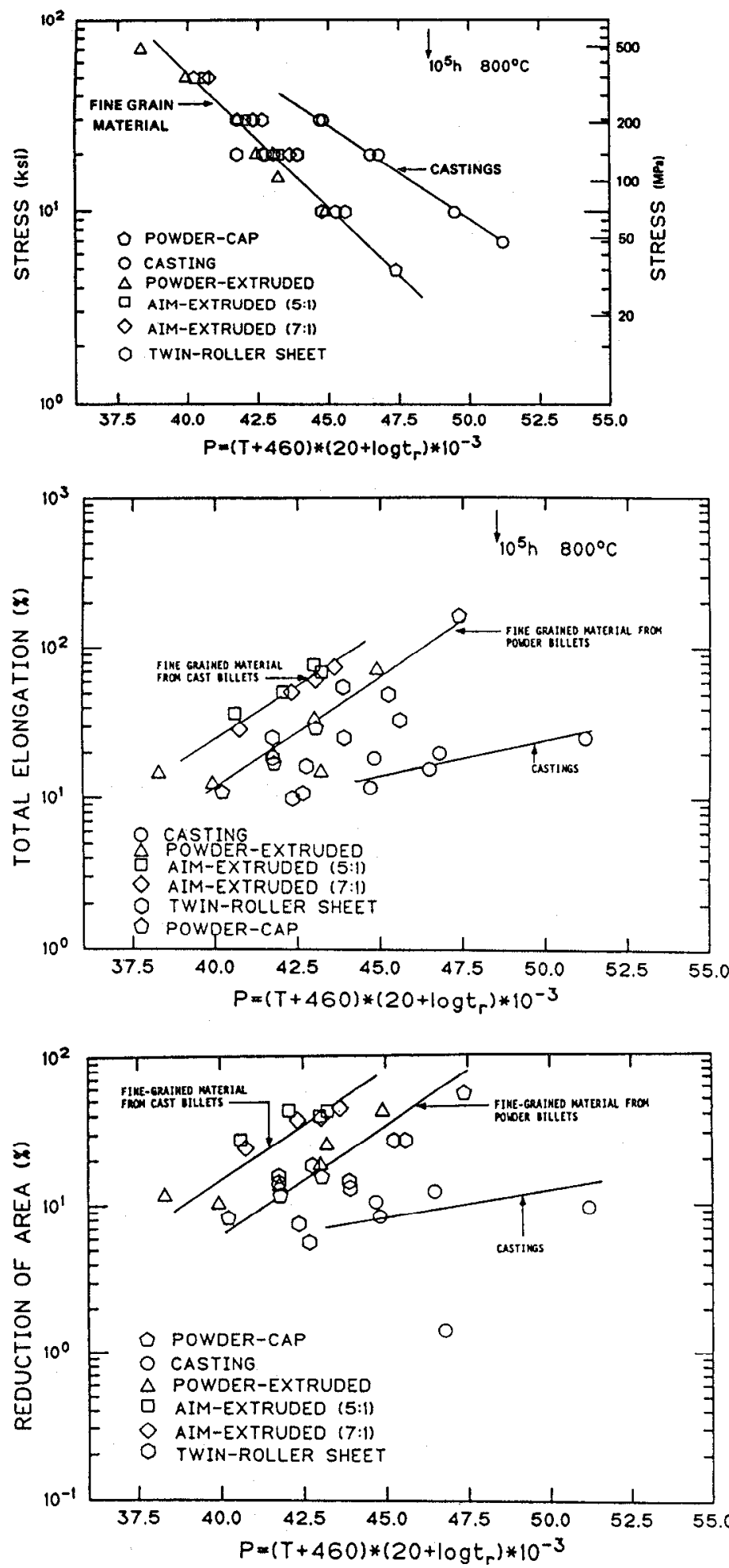

Figure 4 - Larson-Mi1ler parameter of creep rupture properties of IC-221. elongation and reduction of area than the latter at the same parameter.

From this analysis, the $100-$ and 1000 -h rupture strengths at $649,732,816$, and $982^{\circ} \mathrm{C}(1200,1350,1500$, and $1800^{\circ} \mathrm{F}$ ) are listed in Table I for the various products of IC-218 and IC-221 and compared with electroslag cast IC-50. Once again, it is obvious that a coarse-grain cast structure has much superior rupture strength than fine-grain wrought material. The diffusional creep mechanism operative in the test temperature range of this investigation is believed to be responsible for such a significant grain-size effect. The $100^{-}$and $1000^{-h}$ creep rupture strength of the various IC-218 and IC-221 products are compared in Figure 6 with those published for $A-286, N-155, V-57$, Waspaloy, and IN-100 over the 649 to $982^{\circ} \mathrm{C}\left(1200\right.$ to $\left.1800^{\circ} \mathrm{F}\right)$ range. Some IC-218 and IC-22I products are superior and the rest are closely comparable to $\mathrm{A}-286, \mathrm{~V}-57$, and $\mathrm{N}-155$. Some of our products are even comparable to Waspaloy within this range, but above $816^{\circ} \mathrm{C}\left(1500^{\circ} \mathrm{F}\right)$ where the above $\mathrm{Fe}-\mathrm{Ni}-\mathrm{Cr}$ alloys are not used and $\mathrm{Ni}_{3} \mathrm{Al}$ alloys would not be recommended, the nickelbase superalloys (IN-100 and Waspaloy) provide superior creep rupture strength. Again, in all cases, cast products provide higher creep rupture strengths than wrought products.

The Arrhenius plot of the steady-state creep rate versus temperature, Figure 7, for several products of both alloys yields an activation energy for creep of $81.7 \mathrm{kcal}$. This value 

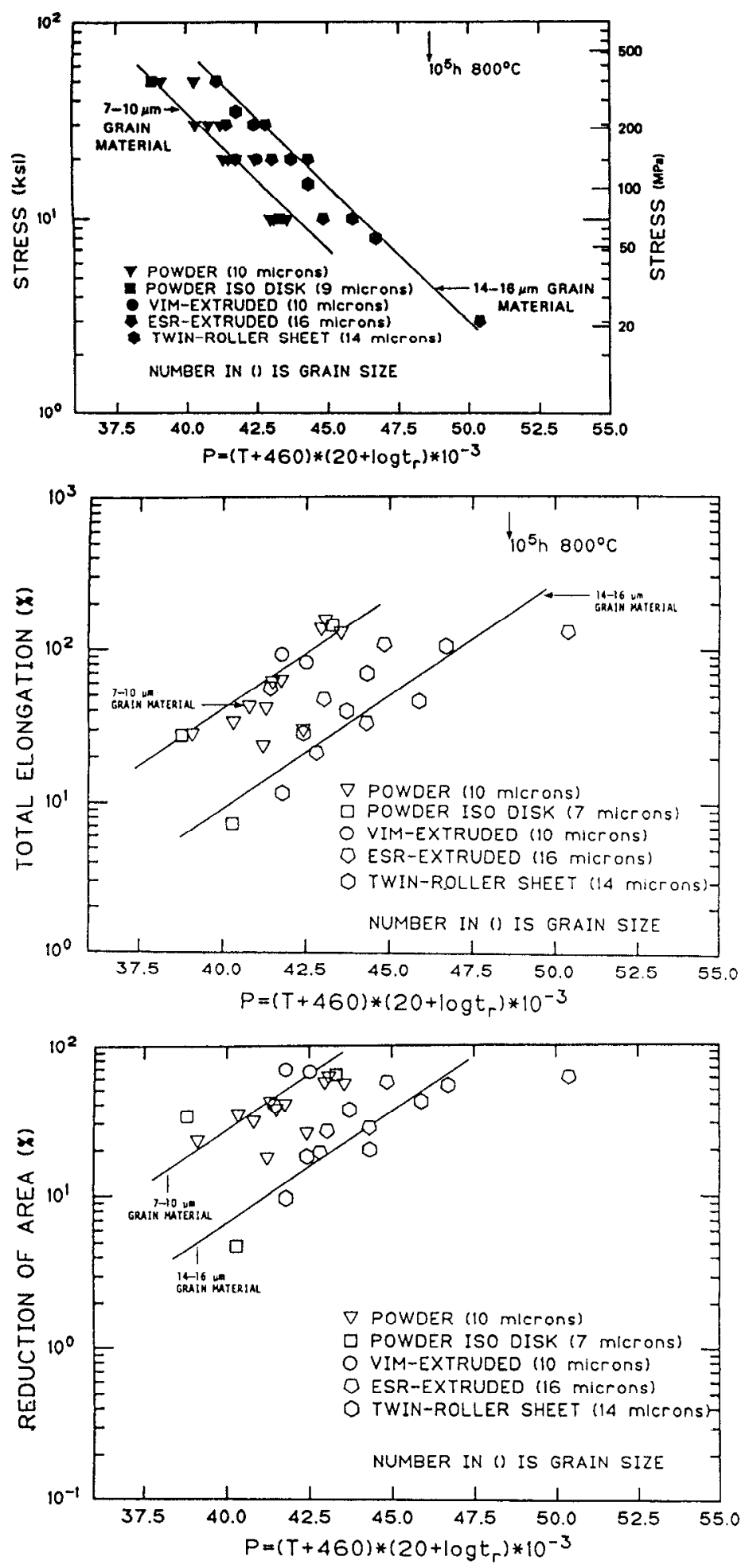

Figure 5 - Larson-Millex parameter of creep rupture properties of IC- 218 . is higher than the published values of self-diffusion of nickel (68 kcal) and riron (70 kcal) but still suggests that the rate-controlling processing in high-temperature creep is diffusion controlled. Analysis of the creep data via the Nabarro-Herring creep mechanism, Figure 8, provides reasonable agreement between predicted and observed values for different grain size materials, and the grain size dependence of creep at high temperature is explained by the Nabarro-Herring creep mechanism which involves lattice diffusion under the action of applied stress.

\section{Discussion}

This paper has presented property data from scaled up quantities of two high-strength $\mathrm{Ni}{ }_{3} \mathrm{~A} 1-\mathrm{CrZr}-\mathrm{B}$ alloys prepared by various techniques. The tensile and creep properties are sensitive to grain-size differences resulting from the various processing techniques, but the alloys still provide an attractive alternative to certain superalloys. The current status of the processes being explored at ORNL in conjunction with industry is that powder processing is closest to commercialization and ideal for fabricating complex shapes. Nickel aluminide can be melted within specifications by the simplest method such as AIM. Secondary melting such as electroslag remelting produces ingots of most desirable grain structure for forging and extruding and of excellent surface quality. Near-net-shape processes from molten metal

offer the best fabrication possibility via the melting route for a variety of shapes. These processes offer the best chance of success for utilization of nickel aluminides in various applications suggested for them. Hot-working processes such as hot forging and hot rolling for the cast products are still not fully developed. Hence, cold processing followed by heat treatment currently has the best chance of success. Among the hot-processing methods, hot extrusion has been investigated most thoroughly and has immediate potential for commercialization. 

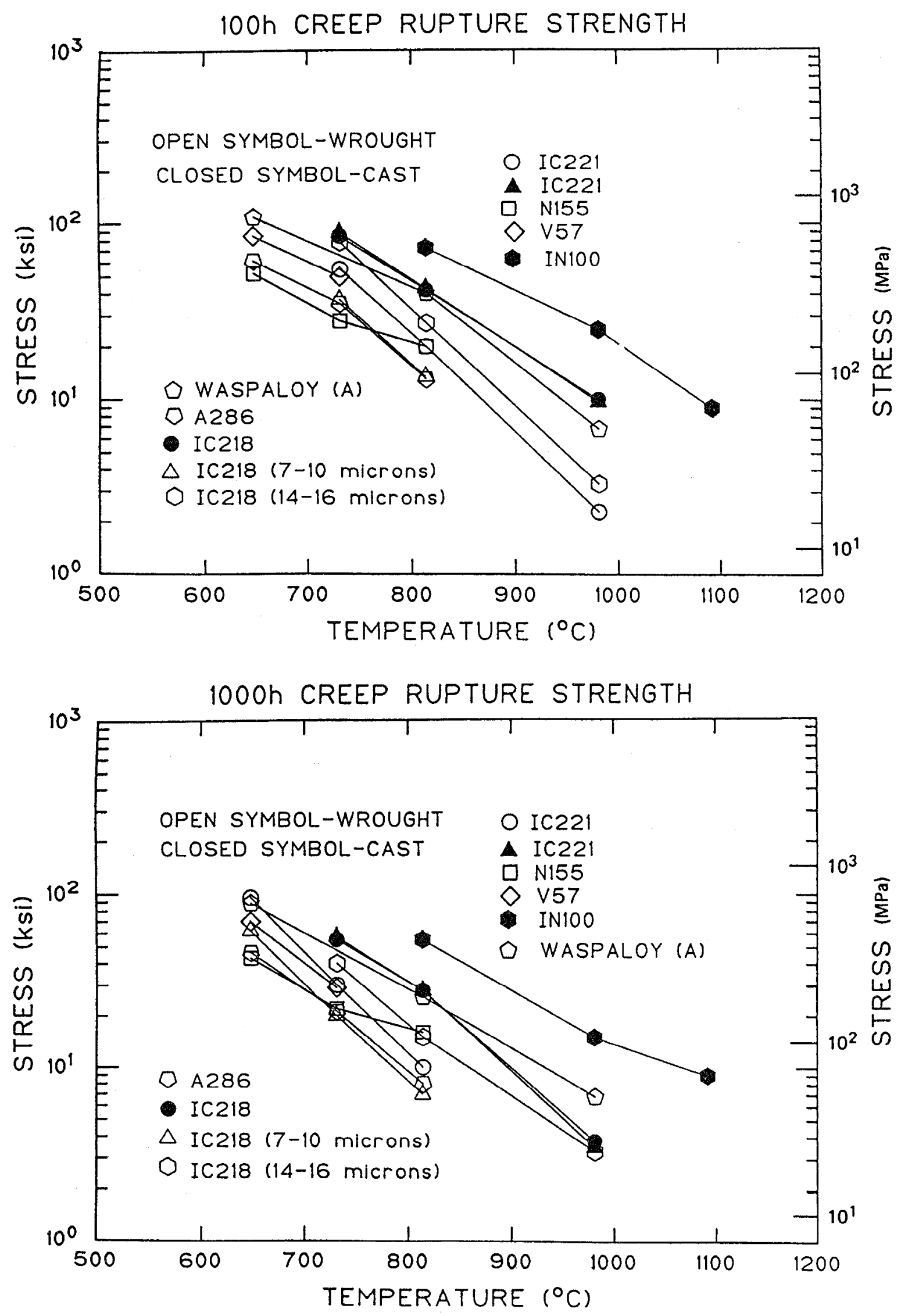

Figure 6 - Comparison of $100-$ and 1000-h creep rupture strength of IC-221 and IC-218 with A-286, N-155, V-57, IN-100, and

Waspaloy. 


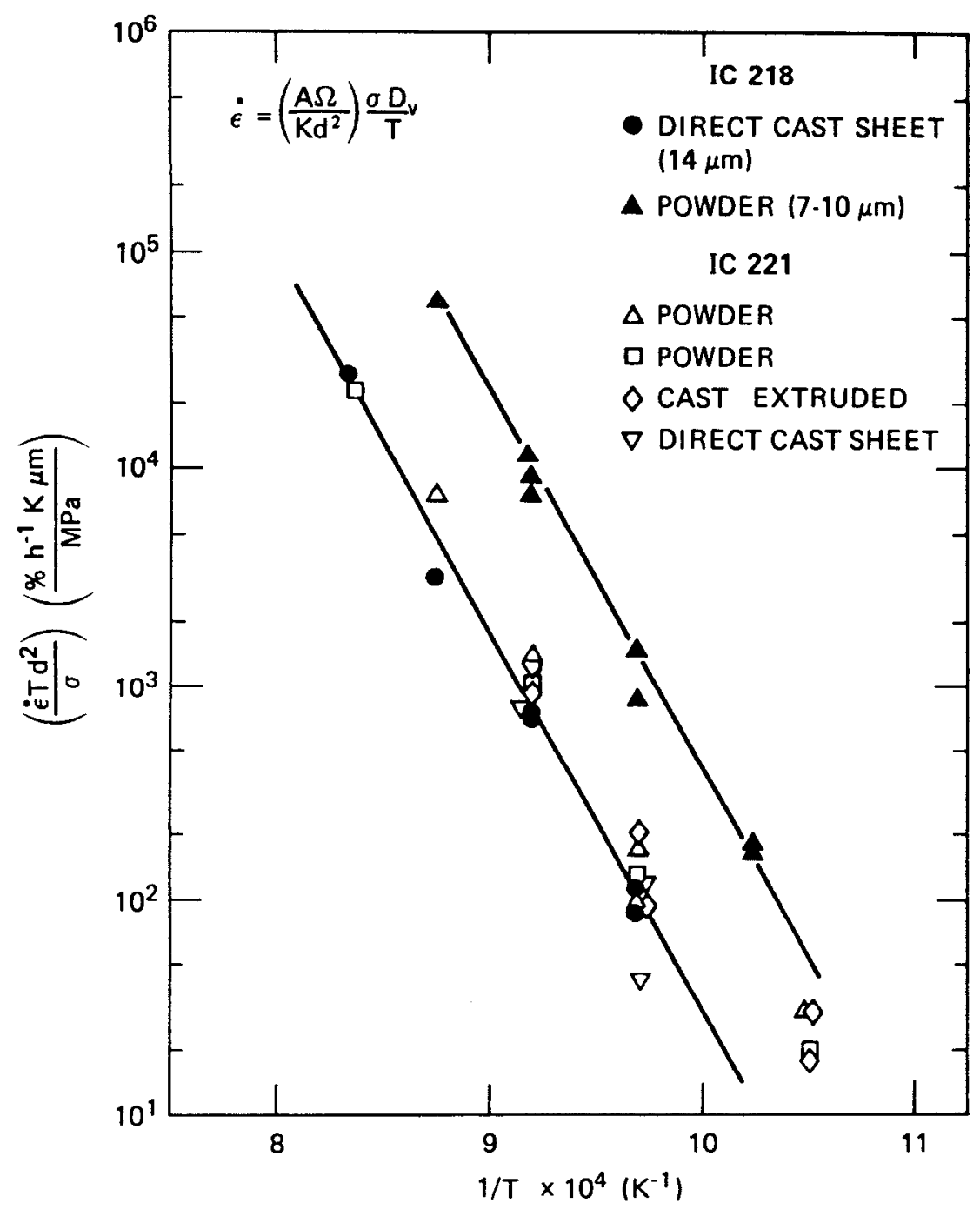

Figure 7 - Arrhenius plot of steady-state creep rate versus temperature.

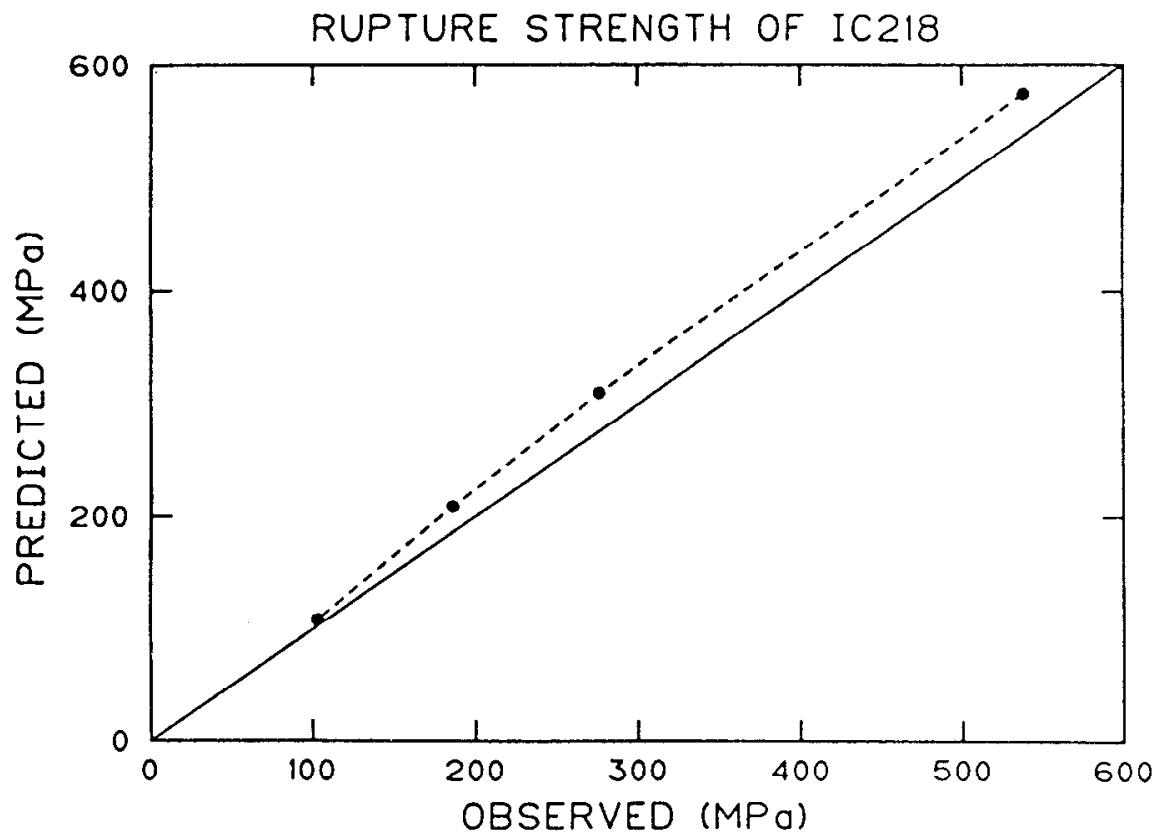

Figure 8 - Plot showing predicted and observed rupture strength of IC-218 a1loy. Values for 15- $\mathrm{m}$ grain size were predicted using Nabarro-Herring equation and data on 10- $\mu \mathrm{m}$ grain size material. Comparison is for data in the temperature range of 732 to $816^{\circ} \mathrm{C}$ and for $100-$ and $1000-\mathrm{h}$ rupture strength. 
Table I. Creep Rupture Strength of Three Nicke1 Aluminides as Affected by Processing

\begin{tabular}{|c|c|c|c|c|c|c|c|}
\hline \multirow{5}{*}{$\begin{array}{c}\text { Temperature } \\
\left({ }^{\circ} \mathrm{C}\right)\end{array}$} & \multirow{5}{*}{$\begin{array}{l}\text { Time to } \\
\text { Rupture } \\
\text { (h) }\end{array}$} & \multicolumn{6}{|c|}{ Stress (MPa) } \\
\hline & & \multirow{4}{*}{$\begin{array}{c}\text { IC-50 } \\
\text { Electros } 1 \mathrm{ag} \\
\text { Cast }\end{array}$} & \multicolumn{3}{|c|}{ IC-218 } & \multirow{2}{*}{\multicolumn{2}{|c|}{ IC -221}} \\
\hline & & & \multirow{3}{*}{ Cast } & \multicolumn{2}{|c|}{ Wrought } & & \\
\hline & & & & & & Cast & Wrought \\
\hline & & & & $7-10 \mu \mathrm{m}$ & $14-16 \mu \mathrm{m}$ & & \\
\hline 649 & 1000 & -- & --- & 427 & -- & -- & 655 \\
\hline 732 & 100 & 310 & 586 & 255 & 538 & 614 & 379 \\
\hline 732 & 1000 & 207 & 379 & 138 & 276 & 393 & 207 \\
\hline 816 & 100 & 172 & 290 & 93 & 186 & 296 & 138 \\
\hline 816 & 1000 & 124 & 193 & 48 & 103 & 193 & 69 \\
\hline 982 & 100 & 37 & 69 & -- & 23 & 67 & 16 \\
\hline 982 & 1000 & 14 & 26 & -- & -- & 24 & -- \\
\hline
\end{tabular}

Acknowledgments

This study was made possible by the generous cooperation of the following companies who provided their melting and processing facilities: Armco, VIM static cast billets; Cabot and CarTech, ESR cast billets; Combustion Engineering, AIM static cast billets and centrifugal cast pipe; Homogeneous Metals, Inc. and Cytemp, PM-extruded billet/bar stock; Ladish and Wyman-Gordon, isothermal forging of PM-extruded bar stock; and Bethlehem, twin-roller cast sheet.

\section{$\underline{\text { References }}$}

1. C. T. Liu, "Development of Nicke1 and Nicke1-Iron Aluminides for ElevatedTemperature Structural Use," Micon 86, 1988, ASTM STP979, 222-237.

2. V. K. Sikka and E. A. Loria, "Deformation Behavior of Powder Metallurgy $\mathrm{Ni}_{3} \mathrm{~A} 1-\mathrm{Hf}-\mathrm{B}, "$ Proceedings, International Symposium on Nickel Metallurgy, CIM, 2 (1986) 293-308.

3. V. K. Sikka, C. T. Liu, and E. A. Loria, "Processing and Properties of Powder Metallurgy Ni ${ }_{3} \mathrm{Al}-\mathrm{Cr}-\mathrm{Zr}-\mathrm{B}$ for Use in Oxidizing Environments," proceedings, Processing of Structural Metals by Rapid Solidification (Metals Park, OH: American Society for Meta1s, 1987), 417-427.

4. V. K. Sikka, "Advances in Processing Techniques for Nickel Aluminides," (to be published in proceedings of First ASM Europe Technical Conference on Advanced Materials and Processing Techniques for Structura1 Applications, Paris, France, 7-9 September 1987).

5. E. M. Schulson, I. Baker, and H. T. Frost, "The Strength and Ductility of Intermetallic Compounds: Grain Size Effects," proceedings, Materials Research Society 81 (1985) 195-205.

6. R. N. Wright and V. K. Sikka, "Elevated Temperature Tensile Properties of Powder Metallurgy $\mathrm{Ni}_{3} \mathrm{Al}$ Alloyed with $\mathrm{Cr}$ and $\mathrm{Zr}$," (submitted for publication in J. Mater. Sci.). 